\section{Mário Krüger}

Departamento de Arquitectura, Faculdade de Ciências e Tecnologia

Universidade de Coimbra 3020-177 Coimbra, PORTUGAL kruger@ci.uc.pt

\section{José Pinto Duarte}

${ }^{*}$ Corresponding author

Faculdade de Arquitectura Universidade Técnica de Lisboa Rua Sá Nogueira

Pólo Universitário, Alto da Ajuda 1349-055 Lisbon PORTUGAL jduarte@fa.utl.pt

\section{Filipe Coutinho}

Departamento de Arquitectura, Faculdade de Ciências e Tecnologia

Universidade de Coimbra 3020-177 Coimbra, PORTUGAL filipecoutinho@hotmail.com
Research

\section{Decoding De re aedificatoria: Using Grammars to Trace Alberti's Influence on Portuguese Classical Architecture}

Presented as a poster at Nexus 2010: Relationships Between Architecture and Mathematics, Porto, 13-15 June 2010.

Abstract. The research described in this paper is part of a project aimed at decoding Alberti's De re aedificatoria by inferring the corresponding shape grammar using the computational framework provided by description and shape grammars to determine the extent of such an influence in the Counter-Reformation period in Portugal. Here we concentrate on the theoretical foundations that enable the translation of Alberti's text into a shape grammar and then use it in determining its influence on Portuguese Renaissance architecture.

Keywords: theory of architecture, shape grammars, Leon Battista Alberti, De re aedificatoria, design automation; rapid prototyping

\title{
Introduction
}

This research project aims to understand the cultural impact of Alberti's De re aedificatoria by using an intelligent computational environment in order to grasp the full implications of that treatise for the architectural practice of classical architecture in Portugal and its overseas territories. In fact, an underlying influence of Alberti's theories is felt in classical architecture in Portugal, but no one has been able to determine the extent of such an influence. The idea is to translate the treatise into a description grammar [Stiny 1981] and a shape grammar [Stiny and Gips 1972] and then trace the influence of Alberti's work by determining the extent to which this grammar can account for the generation of Portuguese classical buildings. This approach follows the "transformations in design" framework proposed by Knight [1983], according to which the transformation of one style into another can be explained by changes in the grammar underlying the first style into the grammar of the second. Grammars are thus proposed as a complementary tool to be used by architectural historians to test hypotheses raised by documentary evidence. In the course of the project, the developed grammars will be implemented as computer programs, and the output digital models will be used to produce drawings, rapid prototyping models and virtual reality models. These elements will form part of an exhibition to be mounted at the end to describe and celebrate Alberti's work and its influence on Portuguese architecture.

\section{State of the art}

A controversial problem exists since there are authors who deny the existence of a Portuguese Renaissance architecture. Actually, Reynaldo dos Santos [1968-1970: II, 175] suggests that the Renaissance is a foreign style which had no influence on the 
development of Portuguese architecture, and Jorge Pais da Silva [1986: 109] makes a direct transition between the Manueline and Mannerist styles without acknowledging the Renaissance period. However, more recently, Moreira [1991; 1995], in studying royal commissions between the Manueline style and the Roman mode of building, was able to identify one hundred and fifty buildings that can be considered as belonging to the Renaissance ambit.

With the help of a proper computational environment this project aims to clarify these issues and to develop a better understanding of Renaissance architecture in Portugal. Several questions can be raised, but the most important is to grasp how an emergent technology such as the construction of a shape grammar can help to spell out an issue that is deeply historically rooted.

The fact is that Alberti's treatise can be thought of as the production of algorithms with the aim of constructing intelligible architectural principles. Let us look, for instance, at the columnatio system as proposed in Book, VII, chap. 7 of the treatise, specifically, on the proportions of the Ionic base (see [Alberti 1988a: 203-204]).

In that case, all the proportional prescriptions of the Ionic base can be transformed into a computer program; in fact, all the issues raised by the dimensions and disposition of architectural elements, such as the column's diameter and its ratios, as well as the position of the torus, the die, the two scotias and rings, can be related within a computational framework in the sense that they are well defined problems and therefore can be spelled out as a set of forms and rules of transformation. Even the Ionic base can be thought of as a consequence of an antecedent form, the Doric base. The same happens with buildings, where, for instance, the sacred buildings described in Book VII are derived from the Roman basilica. In short, antecedent and consequent forms are deeply interrelated within the theoretical framework set out by Alberti.

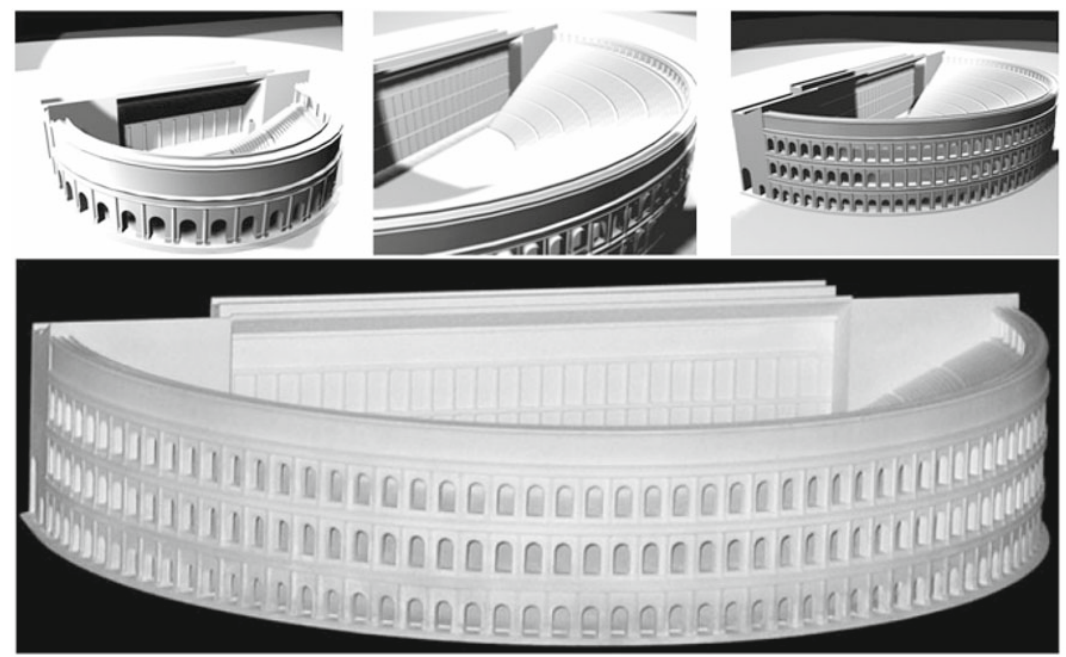

Figure 1 - Outputs of a computer program developed after Vitruvius's Ten Books of Architecture using Autolisp, the scripting language of Autocad. From left to right and from top to bottom: digital models of theatres for 5,000, 10,000 and 15,000 spectators; and a 3D print model of the latter (Tiago Sousa and Duarte Pape, Programming and Fabrication for Architecture course, TU Lisbon, 2002. Instructor: J. P. Duarte) 
These can be explored and developed to translate the rules set out in the treatise as a form of computation, as initially thought by Stiny [1980] and developed more recently, in the case of Siza's houses at Malagueira in Portugal, by Duarte [2001, 2005], using shape grammars to customize mass housing. Shape grammars have already been developed to encode algorithms codified in architectural treatises, for instance, by Andrew Li [2002], who developed a shape grammar after the rules described in a Chinese treatise from the twelfth century. Furthermore, computer programs can be developed from algorithms laid out in classical architectural treatises, as preliminary work developed in the context of a programming class for architects has shown (fig. 1). In this class, students translated the chapter on how to design Roman theaters from Vitruvius's Ten Books of Architecture into a computer program, then used this program to generated a digital 3D model of a theater for a given number of spectators, and finally used this model to produce a physical one using rapid prototyping. This work encompassed an intermediate step to translate the verbal instructions set in the treatise into a parametric model before writing the computer program in Autolisp, the scripting language of Autocad. A similar methodology will be used in the current project for translating Alberti's instructions for designing classical buildings into a computer program and then producing digital and physical models. However, the computational formalism used to translate verbal descriptions into a computer program is a grammar, not a parametric model. The reason for this choice is twofold. The first is a grammar's increased ability to encode complex instructions due to the possibility of combining different description and shape grammars into compound grammars; the second reason is its capacity to describe how to generate a design by sequential rule application, an important feature, given the didactic and pedagogic goals of the project and the aim of showing to which extent Alberti's rules were followed in subsequent Portuguese architecture.

Following this framework, Renaissance architecture in Portugal and in its overseas territories of Brazil and India can be thought as a sort of customization of the rules set out in the treatise by Alberti. That is our fundamental hypothesis for developing a shape grammar of Renaissance architecture in Portugal from the grammar of the original treatise. Work will proceed in five basic stages:

1. Inferring a shape grammar from the text of the treatise following a procedure similar to Li's [2002];

2. Structuring, testing and implementing this grammar with the buildings designed by Alberti as done by Duarte [2005];

3. Acknowledging transformations from the grammar of treatise to the grammar of the buildings designed by Alberti, as is identified by Krüger [2005] and in the notes by Krüger in [Alberti 2011] in a similar mode to that developed by Knight [1994];

4. Understanding the transformations from these sets of rules and forms in order to produce Renaissance architecture in Portugal and in the overseas territories, as is acknowledged by Carita [2008];

5. Implementing an educational software for generating and fabricating designs linking shape grammars and rapid prototyping following the model proposed by Duarte and Wang [2002];

6. Implementing an educational software, with an accompanying exhibition, in order to disseminate widely the results obtained so far. 
Finally, a note on the final result. As there has already been an excellent exhibition of Alberti's works (see the catalogue of the exhibit at Palazzo Te in Mantua [Rykwert and Engel 1994]) using 3D models in wood as well as the CAD implementation of Alberti's buildings, our project can be thought of as a further development of this initial research with the aim of making Alberti's rules operational, but now as a form of computation to understand the architectural transformations that occurred in Portugal during the Counter-Reformation. In that sense, tradition and innovation are united by the idea that computation may play a major role in understanding Renaissance architecture in Portugal and, therefore, in shedding some light on the controversial issues mentioned above, raised by Santos [1968-1970], Silva [1986] and Moreira [1995].

\section{Methodology}

Alberti's treatise is one of the most influential architectural treatises of the Renaissance. Its translation into Portuguese was commissioned by King João III from André de Resende in the sixteenth century but was lost; its influence on Portuguese architecture remains elusive and is the subject of debate among scholars. The recent translation of Alberti's treatise from Latin into Portuguese [Alberti 2011] will provide the basis for determining the extent of such an influence and shed new light on the debate.

The aim of the project is, therefore, to trace the cultural influence of Alberti's treatise on Portuguese classical architecture, and the idea is to use the computational framework provided by description [Stiny 1981] and shape grammars [Stiny and Gips 1972] to determine the extent of such an influence in the Counter-Reformation period. To accomplish this, the following tasks will be necessary:

a. decoding the treatise by inferring the corresponding shape grammar;

b. comparing the grammar of the treatise with the buildings designed by Alberti;

c. tracing the influence of the treatise on Portuguese architecture by mapping the grammar of a particular building type in Portugal and its overseas territories to transformations of the initial grammar for the same type;

d. tracing the impacts of the treatise on the theory, practice and teaching of architecture by mapping the grammars underlying other theoretical and built works to transformations of the initial grammar;

e. disseminating the research results among scholars and the public in general by mounting a visually appealing exhibition using digital media.

A grammar consists of a set of substitution rules that apply recursively to an initial assertion to produce a final statement. In description grammars, the assertions are symbolic descriptions, whereas in shape grammars, they consist of shape descriptions.

The relation between description and shape grammars is such that for each shape rule there is a corresponding description rule and it is therefore possible to translate a description grammar into a shape grammar. Stiny and Mitchell [1978] have pointed out that a grammar can describe the formal and functional structure of a particular architectural style (descriptive value), explain how to synthesize new instances in the style (synthetic value), and determine whether a new instance is in the same style (analytical value). We will refer to these values in developing our research.

Alberti's treatise can be thought of as a set of algorithms that explain how to design buildings according to the canons of classical architecture. The aim is to translate the 
algorithms in the treatise into a description grammar, then into a shape grammar, and finally into a computer program. This is expected to be accomplished with the following four tasks:

1. Task 1, "understanding the treatise," aims at gaining a deep understanding of the treatise by manually designing buildings according to its rules and then producing the corresponding 3D models using rapid prototyping;

2. Task 2, "inferring the grammar," aims at developing the grammar, thereby gaining insight into the formal structure of Alberti's interpretation of classical architecture;

3. Task 3, "implementing the grammar," aims at writing the computer program encoding the grammar; and

4. Task 4, "matching the treatise grammar," aims at matching the grammar with actual buildings designed by Alberti and then with Portuguese classical buildings to determine the extent to which they match.

Knight [1983] has demonstrated that the transition of one particular style into a different but related one can be explained as a transformation of the grammar underlying the first style into that underlying the second by adding, subtracting, or transforming rules. The objective is to trace the influence of Alberti's treatise on Portuguese CounterReformation architecture by determining the extent to which the generation of buildings in this period might be explained by a transformation of the treatise grammar. Work in this stage will concentrate on one building type, possibly churches because they represent the most widely built and studied functional program, which means that there is enough scholarly work to make the current project feasible.

The traditional cultural approach to architectural history relies on the study of documentary sources to trace influences among theoretical and built works in the course of history. This approach is limited when there is not sufficient documentary evidence. An alternative approach is to study the inherent properties or architectural artefacts to determine the similarities and differences between them. This is particularly important in the case of functional and spatial properties which are often overlooked by historians mainly due to the lack of a rigorous methodology, but shape grammars can provide the required technical apparatus. This project aims to bring these two approaches together: namely, to use a cultural approach to trace possible influences of Alberti's treatise on the architecture that followed and then to use grammars to confirm such an influence, focusing on functional and spatial aspects. In addition, it is expected that this effort may constitute a basis for an enquiry into the usefulness of grammars and computational tools for the teaching and practice of architecture today. The aim of this project, therefore, is to trace the impacts of Alberti's treatise on the theory, practice and teaching of architecture by combining cultural and computational approaches.

Furthermore, Alberti recognizes that combinations of architectural elements alone would be meaningless, but joined together they can produce something well-designed, graceful and convenient:

I am accustomed, most of all at night, when the agitation of my soul fills me with cares, and I seek relief from these bitter worries and sad thoughts, to think about and construct in my mind some unheard-of machine to move and carry weights, making it possible to create great and wonderful 
things. And sometimes it happens that I not only calm the agitation of my soul, but invent something excellent and worthy of being remembered. And at other times, instead of pursuing these kinds of thoughts, I compose in my mind and construct some well-designed building, arranging various orders and numbers of columns with diverse capitals and unusual bases, and linking these with cornices and marble plaques which give the whole convenience, and a new grace [Alberti 1988b: III, 114-115].

This strongly suggests that the Albertian approach to generating architectural forms is capable of being developed by a shape grammar, which supports our aim of developing such a grammar within a Portuguese Counter-Reformation context.

\section{Task 1: Understanding the treatise}

This is a preparatory task required for gaining a deep understanding of the treatise. It has three purposes. The first purpose is to make an overall reading of its ten books (or chapters) in order to describe all the features that are capable of having an explicit visual grammar content. The second is to transform these explicit instructions into visual aspects of a grammar that will underlie the construction of a shape grammar such as:

a) to make a clear cut distinction between lineaments, materials and construction;

b) to describe the main differences between public and private buildings;

c) to discriminate between the ornament of sacred, secular and private buildings.

The third purpose is to establish the main guidelines for visually developing Alberti's columnatio system, as well as the overall design strategies in public and private buildings and also in sacred and profane ones.

The aim is to delineate the main lines of inquiry that it is possible to develop in order to transform all the treatise lineaments into algorithms capable of providing an explicit configuration of Alberti's ideas.

This task will be developed in two phases, or subtasks. The first will involve all the researchers in the study of and reflection about the treatise. The second will create drawing models of the architectural building types.

\section{Studying the original treatise and its translations into Portuguese and English}

The seminal inspiration for this work was the translation of Alberti's treatise into Portuguese. As such, most of the work of gathering information has already been done. So, this initial task will simply focus on the study of both the original treatise in Latin, the plates later developed to illustrate the English translation, based on the 1550 Florentine edition of the treatise by Cosimo Bartoli, and the Portuguese edition by Mário Krüger and Arnaldo Espírito Santo, to be published in 2011 by the Calouste Gulbenkian Foundation [Alberti 2011].

\section{Creating 2D and 3D models of the architectural artefacts described in the treatise}

An effective way to understand the treatise is to create $2 \mathrm{D}$ drawings and $3 \mathrm{D}$ models of the described objects, including the column system and whole buildings, by applying the algorithms it describes "by hand". Such an understanding should help to clarify the algorithms and prepare the information for writing the grammars in the next tasks. 
This will enable a deep understanding of the treatise and its translation required for supporting the subsequent work. Secondly, it will generate a set of algorithms and produce visualization material, including $2 \mathrm{D}$ drawings and $3 \mathrm{D}$ models, to be worked on in the next tasks.

Following this procedure a set of algorithms will be extracted that will serve as the basis for the subsequent development of the grammars in task 2. Drawings and models will serve as the basis for the development of the shape grammar by providing visualization material which will facilitate the analysis and comparison of buildings by Alberti with those designed and built within the Portuguese empire.

\section{Task 2: Inferring the grammars}

\section{Grammar corresponding to the orders (columnatio)}

The treatise describes the algorithms that should be followed in the design of buildings according to Alberti's interpretation of classical architecture. This task consists of the translation of the text of Alberti's treatise into shape [Stiny 1980] and description grammars [Stiny 1981], which requires the algorithms' rules to be codified into such grammatical formats.

The research will be concerned, firstly, with the development of a grammar for the column system and secondly with one for a chosen building type.

The classical orders establish a complex system of relations between the various parts and the whole of buildings according to a predetermined system of proportions.

The various parts that compose the column system (columnatio) are tokens of the larger formal language. This task will attempt to uncover the relationships between the Latin language, the original language of the treatise, and the way Alberti defines the canons of his interpretation of classical orders in Book VII. The idea is to write the text in a description grammar format and then write the corresponding shape grammar, thereby determining the algorithms underlying Alberti's treatise.

\section{Grammar corresponding to a particular building type}

The treatise also establishes very clear rules on how to design whole buildings, especially those described in Book VII (ornament to sacred buildings), Book VIII (ornament to public secular buildings), and Book IX (ornament to private buildings). This research will consider a given building type, such as churches, as a case study and then develop the corresponding grammars using the same methodology mentioned above. The grammar should codify the rules for generating both plans and elevations according to the proportioning system defined by the column system (columnatio).

Writing the rules contained in the treatise in grammatical format will systematize them in such a way that it will be possible to check whether Alberti followed such rules in the buildings he designed and will facilitate the development of the computer implementations.

These grammars will be used in Task 3 for comparing the rules Alberti laid down in the treatise with those he followed in the design of actual buildings and in Task 4 for developing the computer implementation. 


\section{Development of 2D and 3D digital representations}

The goal is to build detailed $2 \mathrm{D}$ and $3 \mathrm{D}$ digital representations starting both from the output of the interpreters and from other sources of information, such as existing illustrations of the treatise, and from existing plans and elevations of Alberti's work and of Portuguese buildings influenced by it. This task encompasses the development of drawings, geometric models, texture mapping, scene creation and renderings. Some of the digital representations will be produced manually using the computer, whereas others will be produced as output of the various programs developed in the course of the project. Both types of digital models will be used to produce physical models using rapid prototyping.

\section{Prototyping techniques}

The development of grammars will uncover the rules encoded in the treatise and the computer implementation will permit their exploration. In Book I (Lineamenta), Alberti refers to $2 \mathrm{D}$ drawings and $3 \mathrm{D}$ models as the descriptive elements of building design. The project will therefore use various computer-based technologies for producing these types of elements using cutting-edge techniques. The use of rapid prototyping will enable a more tangible visualization of the output of the interpreters and particularly of Alberti's interpretation of classical architecture, thereby facilitating the fine-tuning of the grammars and increasing the didactic and pedagogical impacts of the research output.

\section{Selection of rapid prototyping techniques}

The purpose of this selection is to experiment with and select appropriate rapid prototyping techniques for producing physical models of the output of the grammar interpreters. Some of the techniques tested and used for the project are already available at partner institutions (laser cutting, 3D printing, $\mathrm{CNC}$ milling, etc.) and some will be acquired within the context of this project to increase the fabrication capabilities during and beyond the current project.

\section{Production of physical models using rapid prototyping techniques}

The objective is to study and illustrate the spatial and formal qualities of Alberti's interpretation of classical architecture and its influence on Portuguese architecture in the Counter-Reformation period. We hope to obtain a better understanding of the complexity of Alberti's thought on implementing and designing sacred and profane buildings, namely on the relationship between discursive and non-discursive thought. That is evident when Alberti invents new terms to describe elements of the column system, such as rudens (rudentura in Portuguese, "cable" in English).

The planned outcome of this task is a set of digital and physical models to be included in the exhibition at the end. These models are necessary first to gain a better understanding of Alberti's treatise and its impact on Portuguese architecture, and then to produce visually appealing material to include in the final exhibition, thereby achieving the didactic and pedagogical goals of the project. This task will result in a Master's thesis.

\section{Task 3: Implementing the grammars}

The codification of the treatise into grammars enables the complete generation of column systems and buildings according to the rules established by Alberti. The implementation of the grammars into computer programs will make such generation 
more efficient and enable the interactive exploration of the space of design solutions defined by the treatise in real time.

\section{Selection of the computer environment}

It will be necessary to choose the computer platform to use in the implementation of the grammars, that is, in the development of the grammar interpreters, including the choice of implementation paradigms and programming language. Based on previous experience in the development of interpreters for similar grammars, the interpreter will probably not need to support emergence, which will make implementation easier and faster to develop. Some of the languages that will be considered are Java, AutoLisp, RhinoScrip, VisualBasic, MaxScript, and Mel script. Among the criteria to be used to choose the language are the type and complexity of the forms to be generated, such as the geometrical intricacy of the Corinthian capital in Book VII, as well as whether to develop a standalone application or a macro within an existing CAD application.

\section{Implementing the grammar of the column system orders}

This task will concentrate on the implementation of the interpreter for the column system orders. The implementation will need to take into consideration issues of interface design to highlight the relations between the shape and description grammars and the complex system of formal relations that they define.

\section{Implementing the grammar of the chosen building type}

This task will focus on the development of the interpreter for the particular building type grammar. As with the column system grammar interpreter, this implementation will need to consider issues of interface design to emphasize and uncover the spatial relations between the elevation and the plan, as well as between the various parts of each $2 \mathrm{D}$ representation.

The result of these tasks will be two computer programs, one implementing the column system grammar and the other a selected building type. These programs will make it possible to test and refine the grammars and explore the universe of solutions defined by the encoded algorithms. They will also be part of the educational software to be implemented, which will focus on the development of the interface for the various programs produced in the course of the project so that their educational capabilities can be enhanced.

\section{Task 4: Matching the treatise grammars}

Although the treatise establishes very clear rules in written format, the lack of illustrations in the editio princeps highlights Alberti's intention to leave room for interpretation when designing real buildings and not jeopardize the accuracy of translating images from one manuscript to another. This task will study and compare built examples designed by Alberti with the treatise's rules in order to identify possible deviations from the canon and attempt to posit hypotheses to explain the source of such deviations.

The aim is to study and compare actual buildings designed by Alberti, namely S. Sebastiano and S. Andrea in Mantua, Malatesta's temple in Rimini, and the Palazzo Rucellai in Florence, with the treatise's rules in order to determine the extent to which the rules in the treatise were followed. This task will rely on Knight's "Transformations 
of Languages of Design" [1983] to explain the deviations rigorously as deletion, addition or transformation of the treatise's grammar rules.

The result will be a map with the eventual transformations of the treatise's grammar to account for the generation of the actual building by Alberti. The map should show which rules were deleted, added, or transformed, and it will serve as the basis to explain why such transformations were required in built examples. This map will then be compared with similar maps developed from the examples designed and built in each of the territories of the Portuguese empire studied. This comparison will help to shed some light on whether the transformations of the treatise within the studied Portuguese territory were due to a need to change the canons to respond to practical building constraints or to local cultural influences.

\section{Mapping the transformations from the De re aedificatoria}

The aim of this task is to map the transformations of the treatise grammar identified in the previous task to the geographical distribution of the selected case studies.

The idea is to be able to explain the geographical differences found in the same architectural type within that geographic area of the Portuguese empire as the successive transformation of the treatise grammar into local grammars and link those transformations to architectural, cultural, political, or other contextual influences.

In this task we will refer again to the framework proposed by Knight [1983] in Transformation in Design, in which the transformation of one style into another is explained by the deletion, addition, or transformation of rules in the initial grammar to obtain the final grammar.

The expected result is an extension of the map of the transformation of the treatise grammar into the grammar of Alberti's built works to encompass the transformation of the previous grammars into the grammars of churches in Portugal, Brazil and India in the studied period. This map is necessary to understand the extent of such transformations and thus of the influence of Alberti's treatise on the architecture of the Portuguese empire. It should also make it possible to formulate hypotheses regarding the source of those transformations, namely building constraints or cultural influences.

\section{Conclusion}

This paper describes the methodology to be followed in a research project whose aim is to determine the extent of Albert's influence on Portuguese classical architecture using a computational framework. Using this framework, the treatise will be translated into a shape grammar with the hope that by verifying the extent to which this grammar can account for the generation of Portuguese classical buildings, it will be possible to determine the extent of Alberti's influence. Specifically, by verifying the number of the treatise grammar rules that are used unchanged to derive a given building type (churches) it will be possible to determine how close the type is to Alberti's canons as set out in the treatise. Conversely, by discovering the number of rules that need to be changed, deleted from or added to the grammar, it will be possible to determine the degree of deviation of the Portuguese case from Alberti's principles. This methodology is proposed for use by architectural historians as a complement to the traditional use of documentary sources. The argument is that grammars might provide a rigorous method to test hypotheses raised by the use of such traditional sources. 


\section{Acknowledgments}

The Digital Alberti project is funded by the Fundação para a Ciência e Tecnologia (FCT), Portugal (PTDC/AUR-AQI/108274/2008), hosted by CES at University of Coimbra, and coordinated by M. Krüger. F. Coutinho is also funded by FCT, grant SFRH/BD/ 66029/2009. We thank T. Knight, G. Stiny, and W.J. Mitchell for their support as consultants to the project. Sadly, W. J. (Bill) Mitchell passed away on June 11 2010. We are deeply thankful for his support to our research over the years. His insight and enthusiasm will be greatly missed.

\section{Bibliography}

AlberTi, Leon Battista. 1966. De Re Aedificatoria (1485). 2 vols., Latin - Italian texts. Trans. Giovanni Orlandi, Intr. and notes by Paolo Portoghesi. Milan: Edizioni il Polifilo.

- 1975. De re aedificatoria. Editio princeps in facsimile. Hans-Karl Lucke, ed. Munich: Prestel verlag.

- 1988a. On the Art of Building in Ten Books. Joseph Rykwert, Neil Leach and Robert Tavernor, trans. Cambridge, MA: MIT Press.

- 1988b. Profugiorum ab aerumna libri III. Della tranquilità dell'animo. (1441/1442) G. Ponte, ed. Genova: Casa Editrice Tilgher.

- 2011. Da Arte Edificatória. Arnaldo Espírito Santo, trans; intr. and notes by Mário Júlio Teixeira Krüger. Lisbon: Calouste Gulbenkian Foundation (in print).

CARITA, Hélder. 2008. Arquitectura Indo-Portuguesa na Região de Cochim e Keral. Lisbon: Fundação Oriente/Transbooks.com.

DUARTE, José Pinto. 2001. Customizing Mass Housing: a discursive grammar for Siza's Malagueira houses. PhD Dissertation, Massachusetts Institute of Technology, Cambridge, MA.

- 2005. Towards the mass customization of housing: the grammar of Siza's houses at Malagueira. Environment and Planning B: Planning and Design 32, 3 (May 2005): 347-380.

DuARTE, José Pinto and Yufei Wang. 2002. Automatic Generation and Fabrication of Designs. Automation in Construction 11, 3: 291-302.

KNight, Terry W. 1983. Transformations in design. London: Cambridge University Press.

. 1983. Transformations of language of design. Environment and Planning B: Planning and Design 10, 2: (Part 1) 125-128; (Part 2) 129-154; (Part 3) 155-177.

. 1994. Transformations in Design: a Formal Approach to Stylistic Change and Innovation in the Visual Arts. Cambridge: Cambridge University Press.

KRÜGER, Mario. 2005. As leituras e a recepção do De Re Aedificatoria de Leon Battista Alberti. http://homelessmonalisa.darq.uc.pt/MarioKruger/ParaumaLeituradoDeReAedificatoria.htm (Last accessed 15 November 2010)

LI, Andrew I-Kang. 2002. Algorithmic Architecture in Twelfth-Century China: the Yingzao Fashi. Pp. 141-150 in Nexus IV: architecture and mathematics, José Francisco Rodrigues and Kim Williams, eds. Fucecchio, Florence: Kim Williams Books.

Moreira, R. 1991. A Arquitectura do Renascimento no sul de Portugal. A encomenda régia entre o Moderno e o Romano. Ph.D. thesis. Lisboa: FCSH-UNL.

- 1995. Arquitectura: Renascimento e Classicismo. Vol II, pp. 302-375 in História da Arte Portuguesa, P. Pereira, ed. Lisbon: Circulo dos Leitores.

RyKWERT, Joseph and Anne EnGEL. 1994. Leon Battista Alberti. Milan: Olivetti/Electa.

SAnTos, Reynaldo dos. 1968-1970. Oito séculos de Arte Portuguesa. 3 vols. s/d. Lisbon: Empresa Nacional de Publicidade.

Silva, Jorge Henriques Pais da. 1986. Paginas de História de Arte. 2 vols. Lisbon: Ed. Estampa.

STINY, George. 1980. Introduction to Shape and Shape Grammars. Environment and Planning B: Planning and Design 7, 3: 343-352.

. 1981. A note on the description of designs. Environment and Planning B: Planning and Design 8, 3: 257-267.

STINY, George and James GIPS. 1972. Shape Grammars and the Generative Specification of Painting and Sculpture. Pp. 1460-1465 in Information Processing 71, C.V. Freiman, ed. Amsterdam: North-Holland. Rpt. in Best computer papers of 1971, O. R. Petrocelli, ed. Philadelphia: Auerbach, pp. 125-135. 


\section{About the authors}

Mário T. Krüger holds a Diploma in Architecture from the Lisbon School of Fine Arts (1972), a Master in Urban Science, University of Birmingham (1973), a Doctorate in Architecture from the University of Cambridge (1977), and a Post-Doc from the Bartlett School of Architecture, University College (1991). Currently he is Full Professor in the Department of Architecture at the University of Coimbra. He has taught at the Technical University of Lisbon School of Architecture, at the Instituto Superior Técnico, and at the University of Brasilia where he was Head of the Department of Urbanism. He has authored over 47 journal articles and 3 books. His most recent work is the annotated translation of Alberti's De Re Aedificatoria. His research interests include the study of Alberti's work and the impact of computation on architectural theory and practice.

José Pinto Duarte holds a B.Arch. (1987) in architecture from the Technical University of Lisbon and an S.M.Arch.S. (1993) and a Ph.D. (2001) in Design and Computation from MIT. He is currently Visiting Scientist at MIT, Associate Professor at the Technical University of Lisbon Faculty of Architecture, and a researcher at the Instituto Superior Técnico, where he founded the ISTAR Labs - IST Architecture Research Laboratories. He is the co-author of Collaborative Design and Learning (with J. Bento, M. Heitor and W. J. Mitchell, Praeger 2004), and Personalizar a Habitação em Série: Uma Gramática Discursiva para as Casas da Malagueira (Fundação Calouste Gulbenkian, 2007). He was awarded the Santander/TU Lisbon Prize for Outstanding Research in Architecture by the Technical University of Lisbon in 2008. His main research interests are mass customization with a special focus on housing, and the application of new technologies to architecture and urban design in general.

Filipe Coutinho holds a Bachelor of Architecture degree from the Technical University of Lisbon Faculty of Architecture (1994) and a Master of Science in Building Technology from the Instituto Superior Técnico (2004). He is currently a Ph.D. student at the University of Coimbra. 